\title{
Eyelid Secretions and the Prevention and Production of Disease
}

\author{
A. J. BRON \\ Oxford
}

\begin{abstract}
Summary
Tears are necessary for the continued health of the ocular surface. Normal constitutents include water, mucin, and lipids, electrolytes, non-electrolytes, and proteins. Lacrimal secretion is under cholinergic control and modulated by sympathetic adrenergic, peptidergic (VIP) and humoral influences; the meibomian glands are innervated, but the goblet cells are not. Retinoids are important for ocular health and prealbumen may be a carrier for vitamin $A$ in the tears to supply corneal epithelium with its requirements. Changes in tear constituents may cause certain ocular disorders. In dry eyes increased osmolarity is thought to cause surface ocular damage but the presence of granulocytes and inflammatory mediators such as prostaglandins and super-oxide may contribute to inflammatory events in this and other external diseases.
\end{abstract}

It has long been accepted that tears are necessary for the continued health of the ocular surface, maintaining the non-keratinised surface essential for corneal transparency and lubrication required for movement of lid on globe. It is a more recent concept that changes in the tear constituents might not only be a reflection of surface eye disease, but a cause of some of its manifestations.

The normal eye is bathed with tears, comprising lacrimal fluid of lacrimal and accessory lacrimal origin to which components of conjunctival and lid origin are added. Tear flow has been estimated variously as $0.3 \mu \mathrm{l} / \mathrm{mm}^{\prime}$ or $1.2 \mu \mathrm{l} / \mathrm{mm} .^{2}$ Reflex secretion is present at birth, though it is said that emotional tears have their onset at about 3 months of life. ${ }^{3}$ Baum has suggested that so-called basal tears are really reflex in nature and that all measured flow is a response at least to some environmental stimulus. In his view basal flow is negligible. Tear flow can be amplified over one hundred-fold in response to irritation. ${ }^{4}$ Tear fluid losses are by bulk lacrimal drainage, evaporation and exchange across the ocular surface.

Wolff's basic 3 layer model for the tear film still holds today in modified form. The bulk of the tears are water, the surface bears a lipid coat and mucin is present in the aqueous phase; however the disposition at the surface of the eye is still in question.

Lacrimal fluid secretion by the lacrimal gland is under neural control of the parasympathetic system via cholinergic fibres, which synapse in the pterygopalative ganglion. ${ }^{5}$ Secretion is modulated by adrenergic sympathetic stimulation by its action on the vascular supply. Lacrimal gland cells also secrete in response to agonists and therefore, presumably to circulating adrenaline.$^{6.7}$ The gland also receives peptidergic innervation by vasointestinal peptide (VIP) ${ }^{8-10}$ and substance $P$ (SP) immuno-reactive fibres. ${ }^{11.12}$ Cholinergic and VIP fibres do not innervate the same receptors, but cholinergic and, adrenergic pathways probably converge on the same second messenger system in the cell, indepen- 
dent of that for VIP. ${ }^{9}$ Humoral factors also influence secretion, so that the glandular secretions in vivo and in vitro are dependent on stimulation by androgens, oestrogens, glucagon ACTH and melanocyte stimulating hormones ${ }^{12}$ which influence not only aqueous and protein production but also glandular size. The lacrimal gland is generally larger in the male. In the rat, ${ }^{14}$ Allansmith and others demonstrated an equal rate of development up to the age of puberty (2.5-5.5 weeks) after which area and density of acini increased in males only. Perifused female rat lacrimal glands secrete less proteins in response to phenylephrine than males, a difference reduced by oophorectomy. ${ }^{15}$ Oestradiol receptors have been demonstrated on lacrimal acini in various species. In rabbit, oophorectomy is followed by acinar degeneration and massive lymphocyte infiltration. ${ }^{16}$ In the rat, tear volume is increased by orchidectomy, an effect blocked by hypophysectomy, but not by thyroidectomy, adrenalectomy or oestrogen administration. ${ }^{17}$ Interactions are evidently complex and probably species dependent. This is likely to be of relevance to age related-changes occurring in the lacrimal gland, particularly in the menopause in women.

Surface tear oils are derived from the oil glands of the lids; these are holocrine in nature and secretion onto the lids can be explained as the result of continuous synthesis and release with breakdown of glandular acini. The analagous sebaceous glands of the skin are affected by levels of sex hormones. ${ }^{18}$

Recently, it has been demonstrated that the meibomian glands receive a rich peptidergic innervation (VIP and SP) for which a neuroregulatory role must be considered. ${ }^{19}$

Mucin is secreted by the goblet cells of the conjunctiva, and mucus glycoprotein has been immunoidentified in human goblet cells using antibody against purified mucin fractions. These fail to label lacrimal gland..$^{20.21}$ The goblet cells are not innervated, but in other parts of the body respond to humoral stimulation by secretin, serotonin, and prostaglandins ( $\mathrm{PGE}_{2}$ and PGD). Retinol is essential to maintain the ocular surface in its nonkeratinised state and maintain goblet-cell density within the conjunctiva. Retinol is delivered to the conjunctiva by the conjunctival vessels and there is presumably the same sequence of retinol carriage by plasma retinol binding protein (RBP) with delivery to a cellular RBP, that exists for other epithelial tissues. For the cornea, which is avascular, another mode of delivery may exist, via the tears. Vitamin A is present in the tears, secreted by the lacrimal gland. ${ }^{22}$ Recently, Chao and Butala have suggested that tearspecific prealbumen, which is present in substantial quantities in the tears, is a binding protein concerned with retinol carriage in the tears and important for the delivery of vitamin A to the corneal epithelium. ${ }^{23}$ This is in keeping with the studies of Thoft and his colleagues who have demonstrated the transdifferentiation of conjunctival epithelial into corneal epithelial cells, with loss of tear goblet population, after resurfacing a total corneal defect by the former cell type. ${ }^{24.25}$ Conversely, this transdifferentiation does not occur if the conjunctival cells re-surface vascularised cornea, presumably because of the higher levels of retinol delivered to the re-surfacing cells in this situation. ${ }^{26,27}$

The table below shows the major categories of tear components. Their role in the prevention and production of disease is now discussed.

\section{Table. Constituents of the Normal Tears}

Water

Lipids: Meibomian; mucin associated.

Mucins: Goblet cell; other?

Electrolytes

Non-electrolytes: Glucose; lactate; amino-acids; urea Proteins: (a) Albumin: pre-albumin

(b) Enzymes: Lysozyme; peroxidase; various glycosidases

(c) Proteases: plasminogen activators

(d) Anti proteases: $\alpha_{1}$ anti-trypsin; $\alpha_{2}$ macroglobin

(e) Immunoglobulins: $\operatorname{lgA}, \mathrm{G}, \mathrm{E}$;

Mediators: Prostaglandins; histamine; complement; $\mathrm{O}_{2}(?)$

Radical Scavengers: Ascorbate; lactoferrin; ceruloplasmin anti-complement

Other materials: Catecholamines; endorphins

Electrolytes: Tear sodium concentration approximates that of the plasma. This value 
does not represent that of lacrimal fluid as secreted since sodium is pumped back across the cornea at least, in exchange for chloride ions, and further modification of concentration arises as a result of evaporation on lid opening. The tears are secreted slightly hypotonic and become hypertonic. Potassium levels are about four times those of the plasma, perhaps, by analogy to the situation in the salivary glands, as a result of secretion of potassium across the lacrimal ductules. It is of interest that ocular surface cells are able to tolerate this high external potassium concentration, which would be lethal to cells exposed to the plasma or extracellular fluid.

Manganese is also present in tears in a concentration which greatly exceeds plasma levels; Tapazo originally found levels of one thousand fold higher ${ }^{28}$ while Frey found a 30 fold difference. ${ }^{3}$ Frey has noted the critical role of the 'salt glands' of the seagull and other birds as an excretory organ, concerned like the kidney in mammals, in electrolyte regulation. He has proposed a similar, though limited, role, for the lacrimal glands in other species including man. He has also suggested that excretion of manganese in copious emotional tears, could influence the emotional state, since this ion has an important function affecting mood. Similarly, he has proposed that the secretion of endorphins in tears could have a similar role. There is not yet strong evidence for such functions but the idea is intriguing.

Recently, Mills and others demonstrated the importance of divalent cation to exotoxin release by gram positive organisms. ${ }^{29}$ They suggest that the fatal toxaemia occurring in women using certain vaginal tampons could result from adsorption of Magnesium ion $(\mathrm{Mg}+)$ by the tampon. Low is a trigger for release of staphlylococal exotoxin. This mechanism could be of relevance in the eye and it would be of interest in relation to contact lens wear.

The tertiary structure of mucous glycoprotein, with its highly negative surface charge, is influenced by the ambient levels of divalent cation such as calcium. Fluctuations in calcium levels, including increases in dry eye could influence mucous glycoprotein rheology and hence that of tears.
Surprisingly, few reliable studies of tear sodium concentration have been made in dry eyes. ${ }^{30}$ Studies by Mengher in Oxford, have shown a small but significant increase in tear sodium compared to normal tears. This is in keeping with studies of tear osmolarity since electrolytes make the major contribution to the osmolarity of the body fluids. It is puzzling that such a rise, attributable to hyperconcentration of tears, is not shown by tear potassium.

Gilbard et al demonstrated in a series of studies that tear osmolarity is increased in dry eye. ${ }^{31}$ This has been reproduced experimentally in the rabbit and rat, with the production, in some ${ }^{32}$ but not all ${ }^{33}$ studies, or surface signs. Gilbard et al have shown that cultured rabbit corneal epithelial cells are damaged by hyperosmolar saline. ${ }^{34}$ Their studies showed normal tears to have a mean osmolarity of $302 \mathrm{mOsm} / \mathrm{L}$ while dry eye tears showed an average increase of $41 \mathrm{mOsm} / \mathrm{L}$. As a diagnostic test, a cut off value of 312 $\mathrm{mOsm} / \mathrm{L}$ had a sensitivity of 76 per cent and specificity of 84 per cent. ${ }^{35}$

The tear mucins (mucous glycoproteins) are responsible for the high relative viscosity of tears (2.92). ${ }^{36}$ Their origin from goblet cells has been proved conclusively in humans, by immunocyto chemical studies using antibodies against a tear mucous glycoprotein fraction $^{20}$ (Moore and Tiffany). This has been confirmed recently by Huang et al, using antibodies to rabbit ocular mucin. ${ }^{21}$ Cross reactivity was demonstrated with antibodies against non-ocular mucins.

Various authors have identified a glycoprotein material in contact with the plasmalemmal surface of the corneal epithelium which is in continuity with similar material in epithelial subsurface vesicles. ${ }^{37}$ The quantity demonstrable is increased after trigeminal nerve section. This appears to be distinct from the thicker layer of material coating the surface of the cornea and designated ocular mucin, and is most likely to be the cellular glycocalyx, though a mucous glycoprotein role is not excluded.

Many roles for the tear mucous glycoproteins have been proposed. Their physical behaviour is non-Newtonian, that is, they shear-thin at increasing shear rates. This has 
been proposed to facilitate lubrication of the ocular surface by reducing viscosity during the blink or saccade.

Recent studies by Mengher, have demonstrated a low viscosity of tears in dry eyes and loss of non-Newtonian features, from which would be inferred a denaturation or a fall in mucus glycoprotein concentration in the tears. This would fit in with the lowered goblet cell ${ }^{38}$ density at the corneal surface in this condition. Further studies have shown a correlation between tear viscosity breakup time and tear surface tension measured by a microtechnique, and NIBUT noninvasive breakup time. ${ }^{39}$ The NIBUT is a measure of tear stability. Since mucous glycoproteins lower the surface tension of the tears it is suggested that a loss of native tear mucous glycoproteins occurs in dry eye which explains a rise in tear surface tension and a fall in stability.

Holly and Lemp proposed that the normal ocular surface is intrinsically hydrophobic and rendered wettable by tear mucin. ${ }^{40}$ This was based on studies in which mucin was 'wiped' from the ocular surface and then replaced, the surface tension of the surface being measured on each occasion. We have recently shown that such studies are unphysiological, since the wiping process damages the surface epithelial cells. ${ }^{41}$ Tiffany has shown for rabbit eye that the surface tension of cornea washed with saline or acetyl cysteine is in the region of 70 $\mathrm{mN} / \mathrm{m}$, and that the removal of surface ocular mucus with acetyl cysteine does not alter this value ${ }^{42} \mathrm{He}$ has suggested, since this value is close to that of water, that mucous glycoprotein is unnecessary to permit wetting of the ocular surface, and that it must therefore, perform some other function. We think that this is one of lubrication.

Loss of conjunctival goblet cells has been documented in a number of non-wetting eye conditions and most profoundly in chemical burns of the eye and in xerophthalmia due to vitamin A deficiency. ${ }^{38,43}$ Vitamin A controls the state of differentiation of mucosal epithelia; in its absence there is a loss of goblet cells, and an increase in keratin content of the cells leading to hyperkeratinisation.

Many proteins in the tears serve a function in preventing microbial and oxidative damage to the surface of the eye. ${ }^{44}$
Lysozyme makes up about $1 / 3$ of the tear proteins. In isolation, it has an anti-bacterial action against a limited number of gram positive bacteria, by punching holes in the peptidoglycan cell wall. Action against gram negative bacteria occurs in conjunction with complement and specific IgG, which lyses the lipopolysaccharide coat of gram negative organisms and gives access to the peptidoglycan cell wall. Lysozyme also interacts with IgA. Its action is facilitated by chelating agents, such as lactoferrin, and it is chemostatic for PMNs, macrophages and monocytes.

Van der Gaag has spoken of the immune responses at the ocular surface; (this issue) and it may be added that secretory $\operatorname{Ig} \mathrm{A}$ has an action similar to that at other mucosal surfaces, coating bacteria and inhibiting the attachment necessary for epithelial invasion. It also renders them mucophilic and encourages entrapment in tear mucus. Its action too is enhanced by lactoferrin. Other specific immunoglobulins are involved in complement-mediated lysis of micro-organisms.

All nine components of complement were detected in the tears by Yamamoto et al and may be involved in bacterial oponisation, bacterial lysis, chemotaxis and phagocytosis of micro-organisms. ${ }^{45}$ This classical pathway is triggered by IgG and IgM complexes, while the alternative pathway can be initiated by IgA complexes, endotoxin, and cell wall polysaccharide (such as that of staphylococci and pneumococci).

Lactoferrin is a potent chelating agent found in other external secretions, but also white cells and other cells. It is secreted by lacrimal glands. Lactoferrin deprives certain bacteria of essential iron (e.g. staphylococci and coliforms) and co-operates in other antimicrobial systems (see above). Ceruloplasmin, is a copper binding enzyme which is also a ferroxidase. It has free-radical scavenging properties, converting superoxide $\left(\mathrm{O}_{2}\right)$ to $\mathrm{H}_{2} \mathrm{O}_{2}$, allowing further degradation. Vitamin $\mathrm{C}$ is also present in tears, at a concentration of 20 times that in the plasma.

With age, lysozyme and lactoferrin levels in the tears fall, while concentrations of ceruloplasmin and $\mathrm{IgG}$ rise. ${ }^{46}$ The former probably reflects a loss of acinar tissue with age, while the latter implies an increase in permeability 
of vascular and other barriers between the subconjunctival compartment and the conjunctival sac.

There is increasing evidence for the presence of mediator substances in the tears. Their potential role is great, though it is often unclear whether their presence simply represents overspill from activated cells at the ocular surface or increased diffusion of material through altered barriers, without any functional implications. Nonetheless, some interesting roles have been proposed, and at the least, their measurement offers the opportunity to sample events occurring at the ocular surface as an index of inflammation. Some of the relevant literature is summarised elsewhere. ${ }^{44.47}$ The presence of complement components in the tears has already been referred to. It is of interest that Kjilstra et al have also identified anti-complementary factors in the normal tears. ${ }^{48}$

Normal tears contain histamine and increased amounts are found in eyes with vernal catarrh and trachoma. Both $\mathrm{H}_{1}$ and $\mathrm{H}_{2}$ receptors have been identified at the ocular surface. ${ }^{49.50}$ Another mast cell product, major basic protein, has also been found in vernal tears and has been mooted as a cause of tissue damage and inflammation in vernal catarrh. ${ }^{51}$ Prostaglandins $\mathrm{PGE}_{2}$ and $\mathrm{PGF}_{2}$ have been found in normal tears and increased $\mathrm{PGF}_{2}$ in both vernal disease and trachoma. Recent studies by Mengher have shown $\mathrm{PGE}_{2}$ in tears of post-operative cataract patients and those with kerato conjunctivitis sicca. ${ }^{39}$ Experimental studies have shown synthesis of $\mathrm{PGE}_{2}$ and $\mathrm{D}_{2}$ and of leukotrienes by conjunctiva. Whatever their role in inflamed conjunctiva, it is plausible that their presence in the tears contributes to the total inflammatory response.

The presence of migrated white cells in tears and conjunctiva is the salient feature of conjunctivitis and the differential nature of the cells involved is of diagnostic importance in distinguishing bacterial from viral causes. White cells however, additionally migrate into the tear sac in other, non-infective ocular states including hay fever conjunctivitis, kerato conjunctivitis sicca, in corneal erosion, post-operative corneal graft and cataract surgery. These are chiefly polymorphonuclear leucocytes and though their degree of activation is not established, it is assumed that they are involved in the release of mediators into the tear film.

Having in mind the presence of a number of free-radical scavengers in tears, we were interested to search for the presence of free radicals themselves in inflammatory states. Using a system to detect superoxide $\left(\mathrm{O}_{2}\right)$, a significant increase above normal was found in both keratoconjunctivitis sicca and postoperative cataract. Polymorphonuclear leucocytes would be one potential source for superoxide.

A final area which has excited considerable interest recently is the presence of potent proteases in the tears ${ }^{52.53}$ which seem to be concerned in the turnover of extracellular matrix and structural proteins during healing ${ }^{54}$ and are perhaps concerned with epithelial turnover, and the patency of ducts, in health. Low levels of proteases are found in normal tears ${ }^{55}$ and antiproteases are also present. Fibronectin and fibrin appear at the surface of the debrided cornea: ${ }^{57}$.Its source is corneal epithelium, though stromal fibroblasts synthesise fibronectin after superficial keratectomy. ${ }^{58}$ Fibronectin provides a necessary substrate for epithelial resurfacing. When resurfacing is completed, these proteins substantially disappear from the cornea. The level of fibronectin in tears is found to rise post-operatively after cataract extraction, ${ }^{59}$ suggesting that this may be a general response to injury of the anterior segment in the human eye and Fibronectin drops have been shown to enhance epithelial healing clinically and experimentally. ${ }^{60}$

Corneal and conjunctival tissues are able to release plasminogen activators into the tears, ${ }^{62}$ and normal tears show such activity. ${ }^{55}$ Tissue plasminogen activator (tPA) derived for instance from endothelial cells, binds strongly to fibrin and is concerned chiefly in fibrinolysis. Urokinase (uPA) produced by many cells, including epithelial, fibroblastic and inflammatory cells, is concerned with events such as tissue modelling and cell migration. After epithelial debridement, tPA, fibrin and fibronectin are complexed at the stromal surface. ${ }^{63}$

High levels of uPA and tPA activity are found in post-operative tears. Berman has 
suggested that in certain situations excessive protease (plasmin) activity in the tears could interfere with epithelial healing, by releasing the cell-binding domain a pentapeptide, GRGDS) from the fibronectin molecule. ${ }^{61}$ This would have the effect of blocking the binding sites of resurfacing epithelium, without affording adhesion to the stromal/Bowman's surface. ${ }^{55}$ In experimental studies they were able to retard epithelial resurfacing of rabbit cornea using topical, synthetic, cellbinding domain pentapeptide. The corollary of this finding lies in the studies of Tervo et al and Salonen et al in which increased levels of plasmin activity were found in a variety of resistant -ulcers and erosions (0.5-20 $\mathrm{mg} / \mathrm{ml}){ }^{64.65}$ Treatment of affected eyes with Trasylol (aprotinin) $\cdot(20,000 \mathrm{iu} / \mathrm{ml})$ an inhibitor of plasminogen activator, was followed by healing in many cases, which was sometimes dramatic. Treatment was associated with a fall in tear plasmin activity. Although this was an open-ended study, the rationale and these early results suggest that a controlled trial of this and other inhibitors would be of great interest.

Plaminogen activator is chemotaxic for leucocytes and could therefore play a part in calling leucocytes to the ocular surface at injury or in other inflammatory states. It also stimulates the production of latent collagenase, for instance in fibroblast cultures and in organ-cultured alkali-burned corneal stroma. It also activates collagenase, which is recognised to have an important role in stromal destruction, after alkali burns. ${ }^{66}$ Plasminogen activator is found chiefly in its latent form in cultured normal corneae, but in its activated form in alkali-burned cornea. This correlates with the negligible collagenase activity in normal cornea and the presence of a high active collagenase in alkali-burned tissue. Once again the possibility of treatment with inhibitors of plasminogen activator or plasmin arises and offers a fruitful direction for clinical research.

The eye is a portal of entry into the body. Many barriers and protective mechanisms exist to prevent damage or infection. They are sometimes breached, and the resulting inflammatory events are signalled clinically and by chemical and cellular changes in the tears.
Measurement of such changes offers insights into future prevention and treatment.

\section{References}

${ }^{1}$ Jordan A and Baum J: Basic tear flow. Does it exist? Ophthalmology 1980, 87: 920-30.

${ }^{2}$ Mishima S, Gasset A, Klyce S, Baum J: Determination of tear volume and tear flow. Invest Ophthalmol 1966, 5: 264-76.

${ }^{3}$ Frey WH: II. Crying. The mystery of tears. Winston Press. 1985

${ }^{4}$ Maurice DM: Structures and fluids involved in the penetration of topically applied drugs. Int Ophthalmol Clin 1980, 20: 7-20.

${ }^{5}$ Ruskell GL: The distribution of autonomic postganglionic nerve fibres to the lacrimal gland in monkeys. J Anat 1971, 109: 229-42.

${ }^{6}$ Botelho SY, Goldstein AM, Martinez EV: Norepinephrine responsive beta-adrenergic receptors in rabbit lacrimal gland. Am J Physiol 1973, 224: 1119-22.

${ }^{7}$ Dartt DA: Cellular control of protein electrolyte and water secretion by the lacrimal gland. The Preocular Tear Film, Ed. F. J. Holly, Pub. Dry Eye Institute, 1986, 358-70.

${ }^{8}$ Dartt DA, Baker AK, Vaillant C, Rose PE: Vasoactive intestinal polypeptide stimulation of protein secretion from rat lacrimal gland acini. Am J Physiol 1984, 247: G502-9.

${ }^{9}$ Dartt DA, Gilbard JP, Rossi SR, Gray KL, Shulman M, Matkin C: Effect of VIP on lacrimal gland and tear secretion in the rabbit. Invest Ophthalmol Vis Sci 1987, 28: (3 Suppl) 156 (Abstracts).

${ }^{10}$ Dartt DA and Ronco LV: Comparison of protein kinase $\mathrm{C}$, Cholinergic, alpha adrenergic and VIPdependant pathways for lacrimal gland enzyme secretion., Invest Ophthalmol Vis Sci 27 (No. 3) suppl 26 Abstr 19.

${ }^{11}$ Nikkinen: The lacrimal gland of the rat and the guinea pig are innervated by nerve fibres containing immunoreactives for substance $P$ and vasoactive intestinal polypeptide. Histochemistry 1984 81: 23-7.

12 Rudich L and Butcher FR: Effects of substance P and elodoisin on $\mathrm{K}+$ efflux, amylase release and cyclic nucleotide levels in slices of rat parotid gland. Biochem biophys Acta 1976, 444: 704.

13 Jahn R, Padell U, Porsch P, Soling HD: Adrenocorticotrophic hormone and alpha-melanocyte stimulating hormone induce secretion and protein phosphorylation in the rat lacrimal gland by activation of a cAMP-dependant pathway. Eur J Biochem 1982, 126: 623

${ }^{14}$ Allansmith MR, Hann LE, Sullivan DA: Age and gender-related differences of the lacrimal gland. Invest Ophthalmol Vis Sci 1987, 28: 156 (Abstr. 1).

${ }^{15}$ Cripps MM, Bromberg BB, Welch MH: Genderdependant lacrimal protein secretion. Invest Ophthalmol Vis Sci 1986, 27: No. 3. Suppl. 25 (Abstr. 17).

16 Jacobs M, Buxton D, Kramer P, Lubkin V, Dunn M, Herp A, Weinstein B, Southern AL, Perry H: 
Rabbit lacrimal gland shows oestradial receptors. Oophorectomised rabbits show lacrimal gland cell vacuolisation and acino description at $8 / 52$ and massive lymphosytic infiltration at 20 weeks. Invest Ophthalmol Vis Sci 1986, 27: No. 3 (Suppl. p. 25).

${ }^{17}$ Allansmith MR and Sullivan DA: Hormonal modulation of tear volume in the rat. Invest Ophthalmol Vis Sci 1986, 27: No. 325 (Abstr. 15).

${ }^{18}$ Schuster S and Thodi AJ: The control and measurement of sebum secretion. J Invest Dermatol 1974, 62: $172-90$.

${ }^{19}$ Hartschuh W, Weihe E, Reinecke M: Peptidergic (neurotensin, VIP, substance P) nerve fibres in the skin. Immunohistochemical evidence of an involvement of neuropeptides in nociception, pruritus and inflammation. Br J Dermatol 1983, 109: Suppl 2, 25: 14-17.

${ }^{20}$ Moore JC and Tiffany JM: Human ocular mucus. Origins and preliminary characterization. Exp Eye Res 1979, 29: 291-301.

${ }^{21}$ Huang AJW and Tseng CG: Development of monoclonal antibodies to rabbit ocular mucin. Invest Ophthalmol Vis Sci 1987, 28: 1483-91.

22 Ubels JL and MacRae SM: Vitamin A is present as retinol in the tears of rabbits and humans. Current Eye Res 1984, 3: 815-22.

${ }^{23}$ Chao CC and Butala SM: Isolation and preliminary characterisation of tear prealbumen from human ocular mucus. Current Eye Res 1986, 5: 895-901.

${ }^{24}$ Shapiro MS, Friend J, Thoft RA: Corneal re-epithelialization from the conjunctiva. Invest Ophthalmol Vis Sci 1981, 21: 135-42.

${ }^{25}$ Friedenwald JS: Growth pressure and metaplasia of conjunctival and corneal epithelium. Doc Ophthalmol 1951, 184: 5-6.

${ }^{26}$ Tseng SCG, Hirst LW, Farazdaghi M, Green WR: Goblet cell density and vascularization during conjunctival transdifferentiation. Invest Ophthalmol Vis Sci 1984, 25: 1168-76.

${ }^{27}$ Tseng SCG, Hirst LW, Farazdaghi M, Green WR: Inhibition of conjunctival transdifferentiation by topical retinoids. Invest Ophthalmol Vis Sci 1987, 28: $538-42$.

28 Tapaszto Istvan: Pathophysiology of human tears. Internat Ophthalmol Clin 1973, 13: 119-47.

${ }^{29}$ Mills JT, Dodel AW, Kass EH: Regulation of staphylococcal toxic shock syndrome. Toxin -1 and total exoprotein production by magnesium ion. Infect Immun 1986, 53: 663-70.

${ }^{30}$ Balik J: The lacrimal fluid in keratoconjunctivitis sicca. Am J Ophthalmol 1952, 35: 773-82.

${ }_{31}$ Gilbard JP, Farris RL, Santa Maria J: Osmolarity of tear microvolumes in keratoconjunctivitis sicca. Arch Ophthalmol 1978, 96: 677-81.

${ }^{32}$ Gilbard J, Huang A, Tseng S, Rossi S, Gray K, Hanninen L: A rabbit model for keratoconjunctivity sicca. Invest Ophthalmol Vis Sci 1985, 26(3): p. 14 (Abstr. 5).

${ }^{33}$ Nelson JD, Peterson TA, Wright JC, AndersonBeckman G: The effects of ligation of the exorbital gland duct on the cornea and exorbital gland of the rat. Invest Ophthalmol Vis Sci 1987, 28: p. 158, (Abstr. 14).

${ }^{34}$ Gilbard JP, Carter JB, Seng DN et al.: Morphologic effect of hyperosmolarity on rabbit corneal epithelium. Ophthalmology 1984, 91: 1205-12.

${ }^{35}$ Gilbard JP and Farris RL: Tear osmolarity and ocular surface disease in keratoconjunctivitis sicca. Arch Ophthalmol 1979, 97: 1642-6.

${ }^{36}$ Bron AJ: Prospects for the dry eye. Trans Ophthalmol Soc UK 1985, 104: 802-26.

${ }^{37}$ Dilley PN and Mackie IA: Surface changes in the anaesthetic conjunctiva in man, with special reference to the production of mucus from a nongoblet cell source. Br J Ophthalmol 1981, 65: 833-42.

${ }^{38}$ Ralph RA: Conjunctival goblet cell density in normal subjects and in dry eye syndromes. Invest Ophthalmol 1975, 14: 299-302.

${ }^{39}$ Mengher LS: Tear assessment in the dry eye Thesis. University of Oxford (Submitted).

40) Holly FJ and Lemp MA: Wettability and wetting of corneal epithelium. Exp Eye Res 1971, 11: 23950

${ }^{41}$ Cope C, Dilly PN, Kaura R, Tiffany JM. Wettability of the corneal surface: a reappraisal. Curr Eye Res 1986, 5: 777-85.

42 Tiffany JM: Measurement of wettability of the corneal surface. Association for Eye Res Meeting. Leuven September 1987. Abstr. 52.

${ }^{+3}$ Sommer A: Nutritional blindness, xerophthalmia and keratomalacia. Oxford University Press (1982).

${ }^{4}$ Bron AJ and Seal DV: Bacterial infection and the eye. The defences of the ocular surface. Trans Ophthalmol Soc UK 1986, 105: 18-25.

45 Yamamoto GK and Allansmith MR: Complement in tears from normal humans. Am J Ophthalmol 1979, 88: 758-63.

${ }^{46}$ Mackie IA and Seal DV: Diagnostic implications of tear protein profiles. Br J Ophthalmol 1984, 68: 321-4.

${ }^{47}$ Bron AJ, Mengher LS, Davey CC: The normal conjunctiva and its responses to inflammation. Trans Ophthalmol Soc UK 1985, 104: 424-35.

${ }^{48}$ Kijlstra A and Veerhuis R: The effect of an anticomplementary factor on normal human tears. Am J Ophthalmol 1981, 92: 24-7.

${ }^{49}$ Abelson $\mathrm{MB}$ and Udell $\mathrm{IJ}: \mathrm{H}_{2}$ receptors in the human ocular surface. Arch Ophthalmol 1981, 99: $302-4$.

${ }^{50}$ Weston JH, Udell IJ, Abelson MB: $\mathrm{H}_{1}$ receptors in the human ocular surface. Invest Ophthalmol Vis Sci 1981, 20(3): (ARVO suppl p. 32).

${ }^{51}$ Udell IJ, Gleich GJ, Allansmith MR, Ackerman SJ, Abelson MB: Eosinophil granule major basic protein and Charcot-Leyden crystal protein in human tears. Am J Ophthalmol 1981, 92: 824-8.

52 Storm T: Fibrinolytic activity in human tears. Scand $J$ Clin Lab Invest 1955, 7: 55.

${ }_{53}^{3}$ Prause J: Serum albumin serum antiproteases and p.m.n. leucocyte neutral collagenolytic protease in the tear fluid of patients with corneal ulcers. Acta Ophthalmol 1983, 61: 272-82. 
${ }^{54}$ Wang HM, Berman M, Law M: Latent and active plasminogen activator in corneal ulceration. Invest Ophthalmol Vis Sci 1985, 26: 511-24.

${ }^{55}$ Rijken D, Wyngaards G, Welbergen J: Immunological characterization of plasminogen activator activities in human tissues and body fluids. $J$ Lab Clin Med 1981, 97: 477-86.

${ }^{56}$ Berman M, Barber J, Langley C: Corneal ulceration and the serum antiproteases I, $\alpha$-antitrypsin. Invest Ophthalmol 1973, 12: 759-70.

${ }^{57}$ Fujikawa LS, Foster CS, Harrist TJ, Lanigan JM, Colvin RB: Fibronectin in healing rabbit corneal wounds. Lab Invest 1981, 45: 120-9.

${ }^{58}$ Phan T-MM, Gipson IK, Foster CS, Zagachin L, Colvin RB: Endogenous production of $\mathrm{FN}$ in corneal stromal wound; An organ culture crossspecies transplant study. Invest Ophthalmol Vis Sci 1986, 27: Suppl 3, p. 52 (Abstr. 4).

${ }^{59}$ Jensen OL, Glund BS, Eriksen HO: Fibronectin in tears following surgical trauma to the eye. Acta Ophthalmol 1985, 63: 346-50.

${ }^{60}$ Nishida T, Nakagawa S, Watanabe K, Yamada K, McDonald J, Otori T, Berman M: Pathobiology of epithelial defects, peptide (GRGDS) of fibronectin cell binding domain inhibits corneal epithelial attachment and spreading on fibronectin. Invest Ophthalmol Vis Sci 1986, 27: Suppl 3, p. 53, Abstr. 7.
${ }^{61}$ Berman M, Manseau E, Law M, Aiken D: Ulceration is correlated with degradation of fibrin and fibrtonectin at the corneal surface. Invest Ophthalmol Vis Sci 1983, 24: 1358-66.

${ }^{62}$ Lantz E and Anderson A: Release of fibrolyte activators from the cornea and conjunctival Albrecht von Graefes Arch Opthalmol 1982, 19: 263-7.

${ }^{63}$ Hayashi K, Berman K, Kenyon K, Pease S: Pathogenesis of epithelial defects and stromal ulceration: localization of tissue plasminogen activator and urokinase-like activator in scraped an alkali burned corneal wound healing models. Invest Ophthalmol Vis Sci 1987, 28: Suppl. p. 2, Abstr. 6.

${ }^{64}$ Tervo T, Salonen EM, Vakeri A: A new therapy to promote corneal healing. Invest Ophthalmol Vis Sci 1986, 27: Suppl. p. 53, Abstr. 10.

${ }^{65}$ Salonen E-M, Tervo T, Torma, Tarkkanen A, Vaheri A: Plasmin in tear fluid of patients with corneal ulcers: basis for new therapy. Acta Ophthalmol 1987, 65: 3-12.

${ }^{66}$ Berman M: Collagenase and corneal ulceration. In, Collagenase in normal and pathological connective tissues. New York John Wiley and Sons (1980), pp. 141-74. 